\title{
Lumbini: The Birth Place of Gautama Buddha
}

Nepal is a country with its unique and diverse blending of history and culture since thousands of years. The mountainous north of Nepal has eight of the world's ten tallest mountains, including the highest point on Earth, Mount Everest, called Sagarmatha in the Nepali language. More than 240 peaks over $20,000 \mathrm{ft}(6,096 \mathrm{~m})$ above sea level are located in Nepal. The southern Terai region is fertile and humid. Lumbini, the birthplace of Lord Gautama Buddha, is located in this region. Lumbini is one of the holiest places of the Buddhist religion; it contains important evidence about the nature of Buddhist pilgrimages dating from as early as the 3rd century BCE.

Lumbini is internationally recognized world heritage site and is situated in Rupandehi District of southern Terai at an altitude of $105 \mathrm{~m}$ above the sea level. It is the place which should be visited and seen by a person of devotion and which should cause awareness and apprehension of the nature of impermanence. The site and its surrounding area is endowed with a rich natural setting of domesticable fauna and favourable agricultural environ.

The birthplace of the Gautama Buddha, Lumbini, is one of the four holy places of Buddhism. It is said in the Parinibbana Sutta that Buddha himself identified four places of future pilgrimage: the sites of his birth, Enlightenment, First Discourse, and death

In the Buddha's time, Lumbini was a beautiful garden full of green and shady sal trees (Shorea robusta). The garden and its tranquil environs were owned by both the Shakyas and the clans. King Suddhodana, father of Gautama Buddha, was of the Shakya dynasty and belonged to the Kshatriya (warrior caste). Maya Devi, his mother, gave birth to the child on her way to her parent's home in Devadaha while resting in Lumbini under a sal tree in the month of May, 642 BC. The beauty of Lumbini is described in Pali and Sanskrit literature. Maya Devi, it is said, was spellbound to see the natural grandeur of Lumbini. While she was standing, she felt labour pains and catching hold of a drooping branch of a sal tree, she gave birth to a baby, the future Buddha.

The site contains the ruins of ancient monasteries, a sacred Bodhi tree, an ancient bathing pond, the famous Ashoka Pillar and the Maya Devi Temple

\section{Bodhi Tree:}

continued to meditate under the Bodhi tree without moving from his seat. During the second week he practiced walking meditation. For another week the
Buddha contemplated the Bodhi tree.

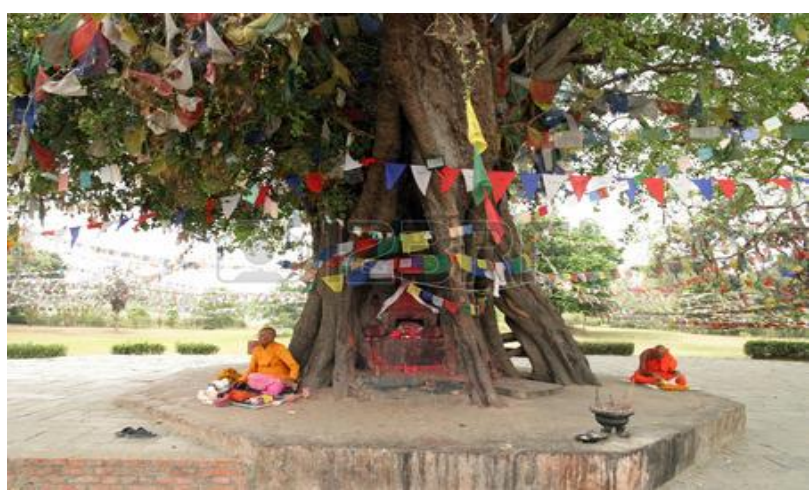

For seven days after the Enlightenment, the Buddha On the back of the main temple situated to the west (see picture) there is an ancient pipal tree Ficus religiosa or Bodhi tree. It was under this tree that Gautama sat for enlightenment. The present tree is considered only as the descendant of the original tree. Many sacred trees in India and other countries are originally raised from seeds brought from the ancient Bodh Gaya tree. While the Vajrasana was the specific site of the enlightenment, the Bodhi tree, closely linked to the Buddha's accomplishment, became a central focus of devotion early in the history of the Sangha. Pilgrims sought the Bodhi Tree's seeds and leaves as blessings for their monasteries and homes.

\section{The Ashoka Pillar}

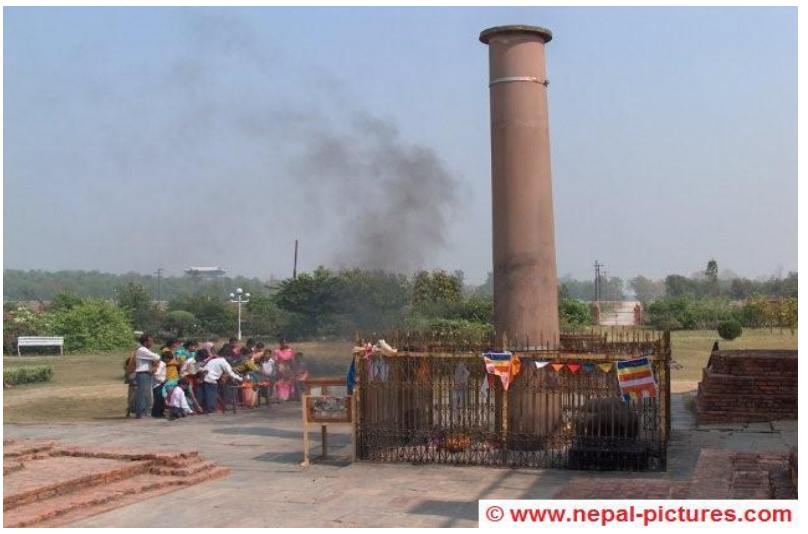

Discovered by the now famous German archaeolgist Dr. Fuhrer, the pillar is the first epigraphic evidence relating to the life history of Lord Buddha and is also the most visible landmark of the garden. The historic importance of the pillar is evidenced by the inscription engraved in the pillar (in Brahmi script). It is said that the great Indian Emperor Ashok visited the site in the twentieth year of is ascendancy to the throne and as a homage to the birthplace,erected the pillar. The inscriptions in the pillar roughly translates as: Kin Piyadesi beloved of the Gods, having been anointed 20 yeas, came himself and 
worshipped saying Here Buddha Shakyamuni was born: And he caused to make a stone (capital) representing a horse; and he caused (this) stone pillar to be erected. Because the worshipful one was born in the village of Lumbini has been made free of taxes and recipient of wealth"

\section{Puskarni-the sacred pool}

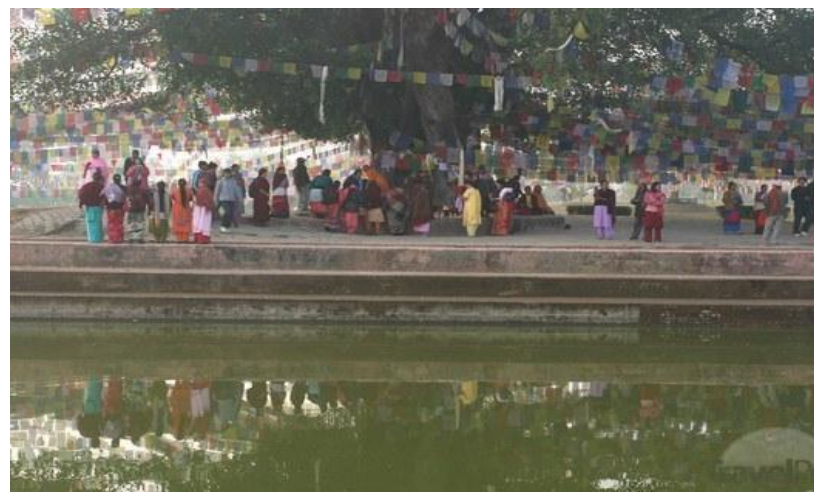

South of the Ashokan Pillar, there is the famous sacred pool- "Puskarni" believed to be the same sacred pool in which Maya Devi took a holy dip just before giving birth to the Lord and also where infant Buddha was given his first purification bath. Architecturally the pool has the projecting terraces in descending order and is reverted with a fine brick masonry.

\section{Sanctum-Sanctorum of the Birthplace}

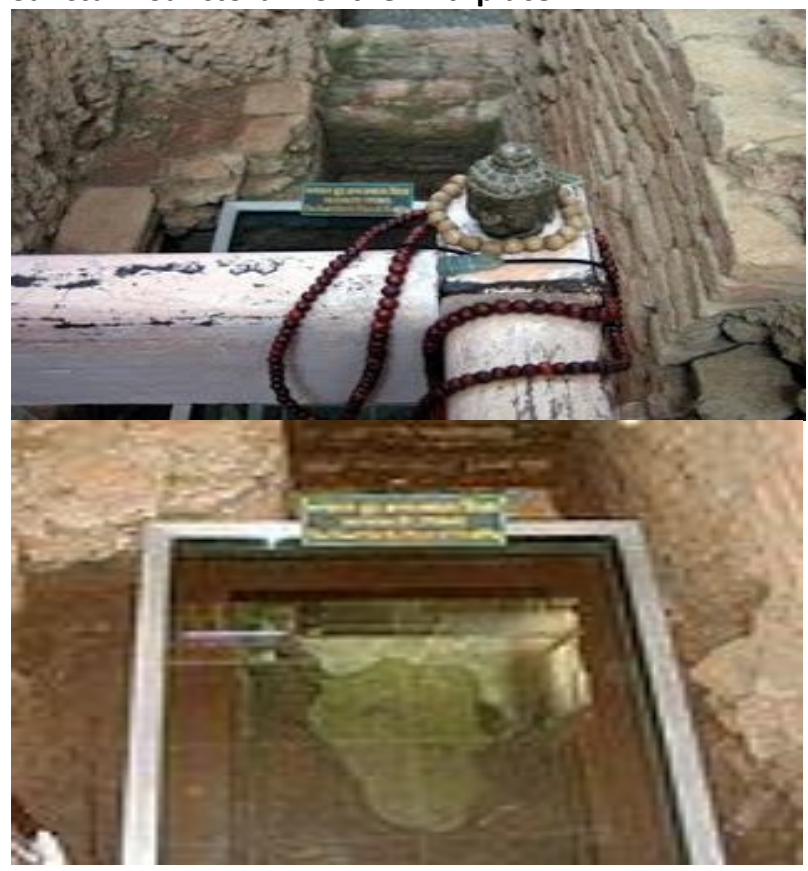

The single most important place of the Lumbini (and to the entire Buddhist world for that matter) is the stoneslab-located deep in the Sanctum sanctorum. Revealed after a hard and meticulous excavations under the three layers of ruins over the site of a famous Maya
Devi temple, the stone slab foundation pinpoints the location of the original place-marking the exact spot of the birthplace of Lord Buddha.

\section{Maya Devi Temple}

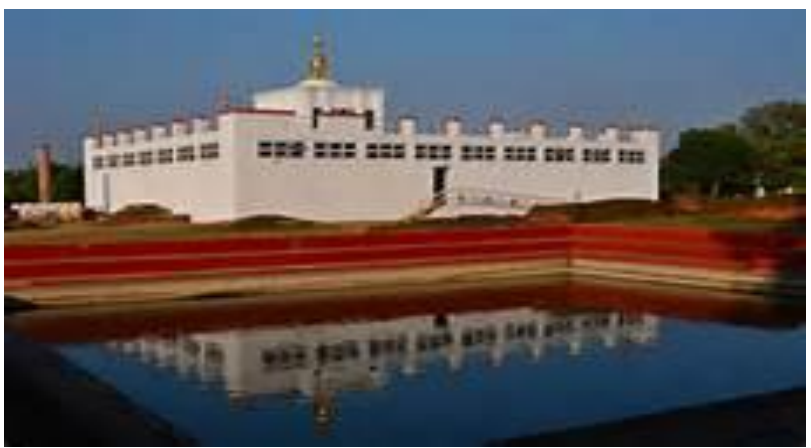

In adition to Ashokan Pillar, the other Shrine of importance is the bas-relief image of Maya Devi, Enshrined in a small pagoda-like structure, the image shows MayaDevi, mother of the Lord. Supporting herself by holding on with her right hand to a branch of Sal tree, with newly born infant Buddha standing upright on a lotus pedestal on an oval halo. Two other celestial figures are depicted in an act of pouring water and lotuses bestowed from heaven.

Earlier the image was placed in the famous white temple of MayaDevi beside the pillar-now totally dismantled to make way for the excavations, which revealed the Sanctum Sanctorum the exact spot where the Lord was born.

\section{Eternal Peace Flame:}

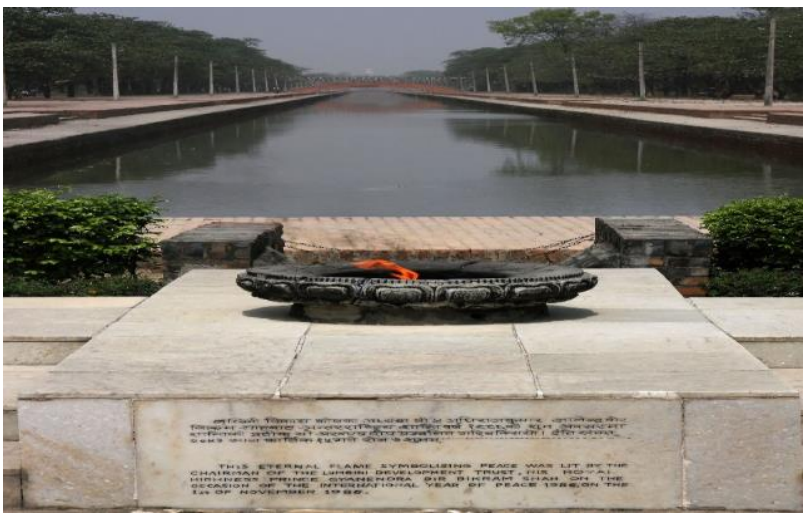

The eternal World Peace Flame is a major attraction of the Lumbini garden located at the centre of the garden. Tourist flock to observe the flame that is kept glowing uninterrupted 24 hours a day. The flame was lighted on 1st November 1986 AD by the then Prince Gyandra Shah. The flame that reprensents peace and fraternity in the world was brought from the United States of America as part of the celebration of the International Peace Year.The eternal flame can be reached at the end of a 10 minutes walk from the Mayadevi . 